\title{
Increased visibility and discoverability of South African health-related research
}

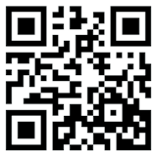

Editors, publishers and researchers gathered in São Paulo, Brazil, in October 2013 to celebrate the 15th anniversary of the Scientific Electronic Library Online (SciELO), a significant developing-country, openaccess publishing project. This subsidised collection of mainly Latin American journals was joined by SciELO South Africa (SA) as its first African extension in 2009.

SciELO SA was established by the Academy of Science of South Africa (ASSAf), and is funded by the Department of Science and Technology. ${ }^{[1]}$ Its aim is to become a fully indexed open-access journal collection in the service of the SA research community through effective quality assurance, worldwide visibility, and amenability to bibliometric analysis. In effect, SciELO SA is set to become a prestigious, free-to-access, freeto-publish, searchable collection of a large number of selected, highquality SA scholarly journals, embedded in the much larger SciELO collections of other member countries. The collection will promote SA research through enhancing the visibility of, and access to, much of the best research. Currently there are 35 scholarly SA journals drawn from many disciplines on the platform, and it is envisaged that eventually as many as $150-180$ titles will be hosted on the platform. Two Health and Medical Publishing Group journals, namely the SAMJ and the South African Journal of Surgery, are already accepted onto the platform.

\section{What does this mean for SA scholarly journals on the SciELO SA platform?}

Since April 2013, the collection has been licensed officially as a certified, locally managed segment of the wider SciELO Network Portal, which is fast becoming the most promising multinational journal indexing and publishing model in the developing world. The system aims to enhance the quality, visibility, reputation and value of national/regional research/ scholarly journals, only a relatively small proportion of which are freely accessible online or are indexed in the well-known indexed databases of Thomson Reuters (Web of Knowledge) or Elsevier (Scopus). This will result in much wider stakeholder usage and collaboration among the SA, regional and global scientific communities.

Thomson Reuters: Intellectual Property and Science announced recently that it is now collaborating with the SciELO Network Portal to integrate the SciELO Citation Index into the Web of Knowledge. ${ }^{[2]}$ This initiative will bring even greater visibility and improved access to research from emerging countries like SA, in turn enabling SA researchers to review and analyse relevant regional content along with that in the top-tier international literature within the Web of Knowledge.

In 2003, the Department of Education (now the Department of Higher Education and Training (DHET)) promulgated the Policy and Procedures for Measurement of Research Output of Public Higher Education Institutions. ${ }^{[3]}$ The purpose of the policy is to 'encourage research productivity by rewarding high-quality research output at public higher education institutions. It must be emphasised that the policy assumes that the research outputs to be recognised are of high (assured) quality, that they are widely accessible across the globe, and that they provide a sound basis for grant making involving public funds, research and development strategies, and high-level human capital development in SA. Peer review is identified as the primary measure of quality for all recognised output, and only journals that appear on certain accredited indexes are accepted for subsidy purposes.

Initially journals were reviewed by the DHET according to a small set of mainly descriptive criteria, but it soon became clear that departmental officials did not have the necessary expertise in the broad range of subject areas to assess the quality of the journals concerned.

For this reason, the DHET approached the ASSAf in 2009 to assist with implementation of its policy by putting new applications for accreditation through the ASSAf's peer review process to ascertain the journals' quality in the context of local and international norms. The ASSAf published a report in 2006 that comprehensively reviewed research publications in scholarly journals. ${ }^{[4]}$ Based on recommendations in this report, the ASSAf developed an appropriate methodology for a discipline-grouped, independent, multiple-peer review of local journals, overseen by council-appointed peer review panels. This was to be followed by the release of formal consensus reports. To date, over 130 journals have been, or are being, subjected to this process. (The above-mentioned ASSAf quality assurance process is the same one used when evaluating journals for DHET accreditation.)

It is also worth mentioning that the ASSAf's peer review panel for the health sciences and related medical journals has just completed its review and will publish its report by mid-2014. The panel dealt with a total of 35 journals, of which 22 call themselves South African, 6 southern African and 5 African; only 1 is an international journal in the sense that it is the official journal of an international organisation but is published in SA, while the remaining journal does not refer to its target area in its title. Accordingly, most of the journals publish mainly local authors, and the content is focused heavily on local issues and topics. However, some titles have definitely become important owing to their continental reach, with their authors drawn from many African countries, and the quality and breadth of their articles reflecting a wide focus (e.g. HIV and AIDS research). The majority of the journals (33) are published online and only two are exclusively published as hard/ print copies. The peer review panel generally felt that the quality of the research articles published in this collection of SA health sciences and related journals was generally 'good to very good', and that the processes and policies of the journals were generally sound.

It is therefore hoped that the global reach and potential impact of scientific research in SA will be greatly enhanced by these efforts to boost the quality and quantity of work that is locally published, and that this work will increasingly be made available on the SciELO SA platform and its connected international indexing services.

\section{$S$ Veldsman}

Director of the Scholarly Publishing Unit, ASSAf, South Africa

\section{W Gevers}

Co-ordinator of the peer review panels and Advisor to the ASSAf Council on Scholarly Publishing in South Africa (CSPiSA), South Africa

Corresponding author: W Gevers (wieland@telkomsa.net)

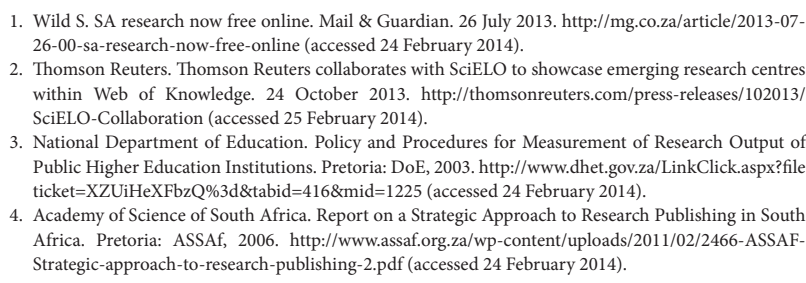

1. Wild S. SA research now free online. Mail \& Guardian. 26 July 2013. http://mg.co.za/article/2013-07-

26-00-sa-research-now-free-online (accessed 24 February 2014). within Reuters. Thomson Reuters collaborates with SciELO to showcase emerging research centre within Web of Knowledge. 24 October 2013. http://thomsonreuters.com/press-releases/102013/
ScieLO-Collaboration (accessed 25 February 2014).

. National Department of Education. Policy and Procedures for Measurement of Research Output of Public ticket $=$ XZUiHeXFbzQ\%3d\&tabid=416\&mid=1225 (accessed 24 February 2014).

Academy of Science of South Africa. Report on a Strategic Approach to Research Publishing in South Africa. Pretoria: ASSA, 2006. Hep./Nww.assaf.org.za/wp-content/uploads/2011/02/2466-ASSAFStrategic-approach-to-research-publishing-2.pdf (accessed 24 February 2014).

S Afr Med J 2014;104(4):287. DOI:10.7196/SAMJ.7934 